\title{
Water Bodies Extraction and Terrain Analysis for Finding Critical Water Scarcity Locations using Elevation Data
}

\author{
B.G. Kodge \\ Department of Computer Science, S. V. College, Udgir, Maharashtra, India \\ E-Mail: kodgebg@hotmail.com
}

\begin{abstract}
The present study is aimed to create some new methods for extraction of water bodies (Rivers and Reservoirs) and analyze the land formation of terrain using elevation data. The digital elevation models (DEM) are used to extract water bodies and create terrain contours for finding water scarcity locations. Further this work also used some geospatial villages related data to obtain and analyze how many villages are suffering from critical water scarcity problems under the found water scarcity locations. The village's data also highlights all village's in which they fell under critical water scarcity regions and facing agriculture and drinking water problems, with respect to their elevation data and available nearby natural water resources.
\end{abstract}

Keywords: GIS, Pattern recognition, DEM, Water scarcity, spatial data

\section{INTRODUCTION}

Continuous overexploitations of natural resources like land, water and forest have caused serious threat to the local population of the semiarid region. Thus, problems like little scope for, declining ground water level and shortage of drinking water prevail. In this study an attempt has been made to estimate the availability of water resources and water scarcity regions using advanced topographic mapping techniques.

Topography is basic to many earth surface processes and thus finds applications in ecology, hydrology, security, agriculture, climatology, geology, pedology, geomorphology and a host of other domains and constitutes the basis for explaining processes and predicting them through the process of modelling. The tremendous role of topographic mapping in national development continues to receive recognition by national, state and local governments the world over. The importance of topographic mapping as a national project is therefore growing and accurate topographic maps as its major products are considered as indispensable components of national geospatial data infrastructure. In countries with developed and stable economies, a clearly articulated road map is usually made for regular, fresh topographic mapping using current data and the state-of-the-art mapping technologies. In lessdeveloped countries however, the problem of poverty and inadequate technical capacities in the area of geoinformation production and management culminate in the inability of such countries to carry out fresh topographical mapping at regular time intervals using expensive but accurate topographical mapping techniques. For such countries, an alternative and cost-effective strategy over the years has been topographical map revision using existing topographical maps, satellite imageries and other readily available spatial data sources. Unfortunately, the process of extracting topographical information (contours) from existing topographical maps and integrating same in a new digital topographical map, often at a larger scale, is usually a lengthy and time-consuming process due to differences in map units and contour intervals between the existing base maps and the new map. Moreover, most of the topographical map sheets to be used as base maps for a revision exercise are either missing or, where they exist, are very old and suffer from severe distortion. A recent development representing a tremendous forward leap in remote sensing technology that will significantly eliminate some of the lacunae associated with topographic map revision from existing topographical maps is the launching of the Shuttle Radar Topography Mission (SRTM) in February, 2000.

A digital elevation model (DEM) is a digital representation of a terrain's surface - commonly for a planet (including Earth), moon, or asteroid - created from terrain elevation data. Using the Synthetic Aperture Radar (SAR) interferometry to produce the first near-global high resolution digital elevation model (DEM) of the Earth, SRTM has created an unparalleled set of global elevations that is freely available for modelling, aping and environmental applications (Gorokhovich and Voustianiouk, 2006). The global availability (about $80 \%$ of the Earth surface, covering land masses between $60^{\circ} \mathrm{N}$ and $56^{\circ} \mathrm{S}$ ) makes it the most widely-used set of baseline elevation information for a wide-range of applications and this development has been identified by professionals in the geo-information arena as a significant landmark that will tremendously revolutionize medium-scale topographic mapping.

The near-global SRTM digital elevation model (DEM) product was processed and compiled at a resolution of $90 \mathrm{~m}$ by the Consultative Group for International Agriculture Research Consortium for Spatial Information (CGIAR-CSI) and hosted on a Web portal for free public access and download. Although this product presents attractive promise for terrain analysis for an impressively wide range of applications, several researchers have proposed a thorough evaluation of its vertical accuracy. 


\section{AREA OF RESEARCH STUDY}

Latur District is in the south-eastern part of the Maharashtra state in India. It is well known for its Quality of Education, Administration, food grain trade and oil mills. Latur district has an ancient historical background. The King 'Amoghvarsha' of Rashtrakutas developed the Latur city, originally the native place of the Rashtrakutas. The Rashtrakutas who succeeded the Chalukyas of Badami in 753 A.D called themselves the residents of Lattalut. Latur is a major city and district in Maharashtra state of India. It is well known for its quality of education, administration, food grain trade and oil mills. The district is divided into three sub-divisions and 10 talukas (sub-districts) [1].

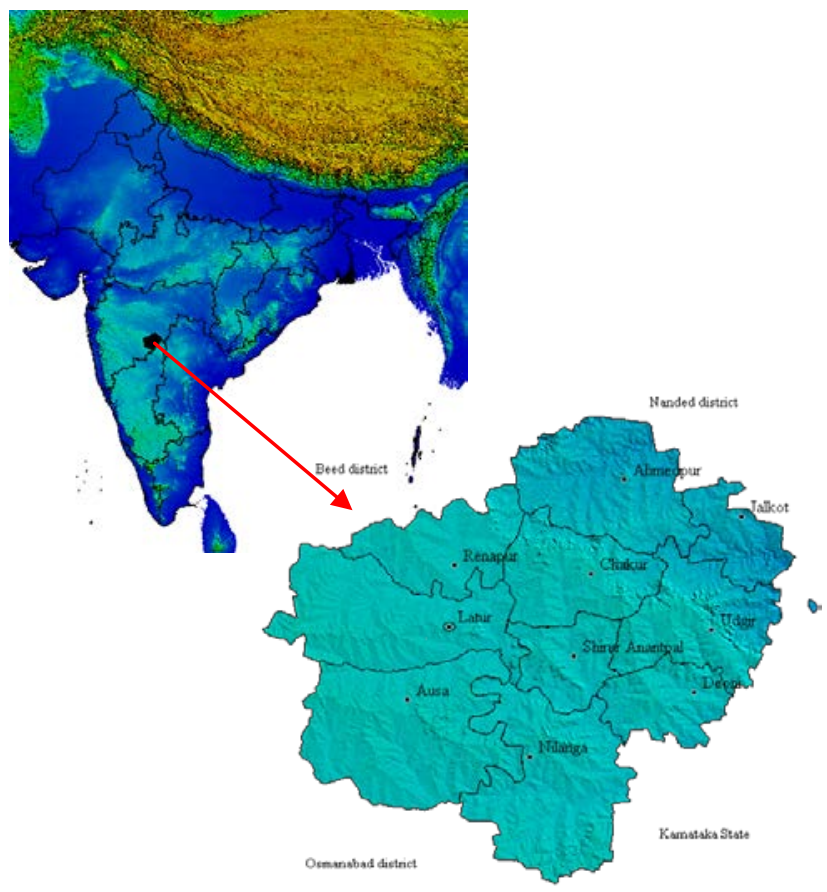

Fig. 1 Location of Latur district in India

Latur is located at $18^{\circ} 24^{\prime} \mathrm{N} 76^{\circ} 35^{\prime} \mathrm{E} / 18.4^{\circ} \mathrm{N} 76.58^{\circ} \mathrm{E} / 18.4$; 76.58 as shown in Fig.1. It has an average elevation of 551 meters (1807.74 feet). The district head quarter is situated at 636 meter above mean sea level. The district is situated on Maharashtra-Karnataka state boundary. On the eastern side of the Latur is Bidar district of Karnataka, whereas Nanded is on the Northeast, Parbhani district on the northern side, Beed on the Northwest and Osmanabad on the western and southern side. The entire district of Latur is situated on the Balaghat plateau, 415 to 700 meters from the mean sea level.

\section{DATA, MATERIALS AND METHODS}

\section{A. Source Data}

The study employed in this paper are with three major sources of spatial data (90-m resolution CGIAR-CSI SRTM digital elevation data, $1 / 50,000$ topographical map of the study site and contour lines randomly distributed over the study site).

The SRTM Digital Elevation Model was processed and maintained by the Consultative Group for International Agriculture Research Consortium for Spatial Information (CGIAR-CSI). In the form compiled and maintained by CGIAR-CSI, the SRTM elevation data have a spatial resolution of $90 \mathrm{~m}$. This data set is seamless with all voids filled using a methodology based on spatial filtering (Gorokhovich and Voustianiouk, 2006). The CGIAR-CSI SRTM 90m digital elevation data sets are provided to the general public in $5^{\circ} \mathrm{X} 5^{\circ}$ tiles in computer-compatible raster formats (GeoTiff and ARC/INFO ASCII Grid). The data set is in LatLon coordinate system projected on the WGS 84 Ellipsoid. For the purpose of our study, one of the tiles covering the chosen study site was downloaded from the CGIAR-CSI Web site at http://srtm.csicgiar.org.

One topographic map sheet at the scale of $1 / 50,000$ covering the chosen study site was selected for use as a reference for analyzing the SRTM elevation data. The map sheet was digitized into different layers as part of the input data sets within the framework. The maps are based on the UTM projection (Zone 43) on WGS 1984 Ellipsoid and had a contour interval of 25 feet.

\section{B. Materials}

Five major software packages were employed for the processing of the data and the visualization and analysis of the results. These included the MATLAB, open-source Integrated Land and Water Information System (ILWIS 3.4), Quantum GIS (QGIS) 1.6, Natural Resource Data Base (NRDB 2.7) and Microsoft Excel. In addition, we developed a number of in-house programs in Visual Basic 6.0 for performing some specialized functions such as coordinate transformation, terrain profiling and elevation data extraction from ASCII raster data sets.

\section{Methodology}

Quantitative statistical and geostatistical tests were performed on the two spatial data sources for different terrain configurations and contexts to determine their suitability for topographical mapping in different scenarios. In particulars of this study consisted of:

1. Measuring the vertical accuracy of the DEM derived from the 1:50,000 topographic map and that of the 90$\mathrm{m}$ resolution CGIAR-CSI SRTM digital elevation data against higher precision GPS measurements within the same site;

2. Interpolating digital elevation models from an existing topographic map covering the same area and comparing measurements from the two sources;

3. Implementing a processing strategy to minimize errors emanating from contour interpolation using SRTM data as a base.

4. Contour lines generation with 25 meters interval; 
5. Extraction of water bodies from DEM.

6. And finding which villages fell under critical water scarcity regions of the study site.

The data sets employed in this study emanated from disparate sources based on different formats, coordinate systems and projections. The first step in the exploitation of the data sets was therefore the transformation of all the data sets into a common system. Since the CGIAR-CSI SRTM 90m digital elevation data sets were in LatLon WGS84 system, the topographic map layers (contours and rivers) and the GPS elevation data in UTM Clarke 1880 system were transformed into the LatLon WGS84 system using tools available in ILWIS 3.4 software. The QGIS 1.6 is used to process DEMs and polyginze them to find the waterbodies/lakes of the study site for finding water scarcity zones. In MATLAB we processed the raster map (JPG) of DEM to extract the river basins. And finally all the processed data imported into our local spatial data base to find out the villages which fell under the critical water scarcity zones

\section{LAND ELEVATION CONTOURS}

Contouring is the most common method for terrain mapping. Contour line connects points of equal elevation, the contour interval represents the vertical distance between contour lines, and the base contour is the contour from which contouring starts. Contour lines are lines drawn on a map connecting points of equal elevation. The contour line represented by the shoreline separates areas that have elevations above sea level from those that have elevations below sea level.

We refer to contour lines in terms of their elevation above or below sea level. Contour lines are useful because they allow us to show the shape of the land surface (topography) on a map. Suppose a DEM has elevation readings from 362 to 750 meters. If the base contour is set to 400 and the contour interval at 100 , then contouring would create the contour lines of 400, 500, 600 and so on. Contour lines can be drawn for any elevation, but to simplify things only lines for certain elevations are drawn on a topographic map [1]. The contour interval is constant for each map. It will be noted on the margin of the map. One can also determine the contour interval by looking at how many contour lines are between labelled contours.

Latur district is situated on Balaghat ranges and has minimum 415 and maximum 700 meters of heights. The Latur district has 551.15 meters (1808.23 feet) of average elevation. The above said heights are generated in contour lines/areas and stored in Latur district spatial database. The areas of specific heights, mean elevation, standard deviation of area and standard deviation of elevation are shown in Table 1. The process of generating contour lines/area using digital elevation models are performed in Quantum GIS 1.6. The vector maps of elevation contour lines/area of Latur district is generated with 25 meters of intervals and are shown in below figure 2 .

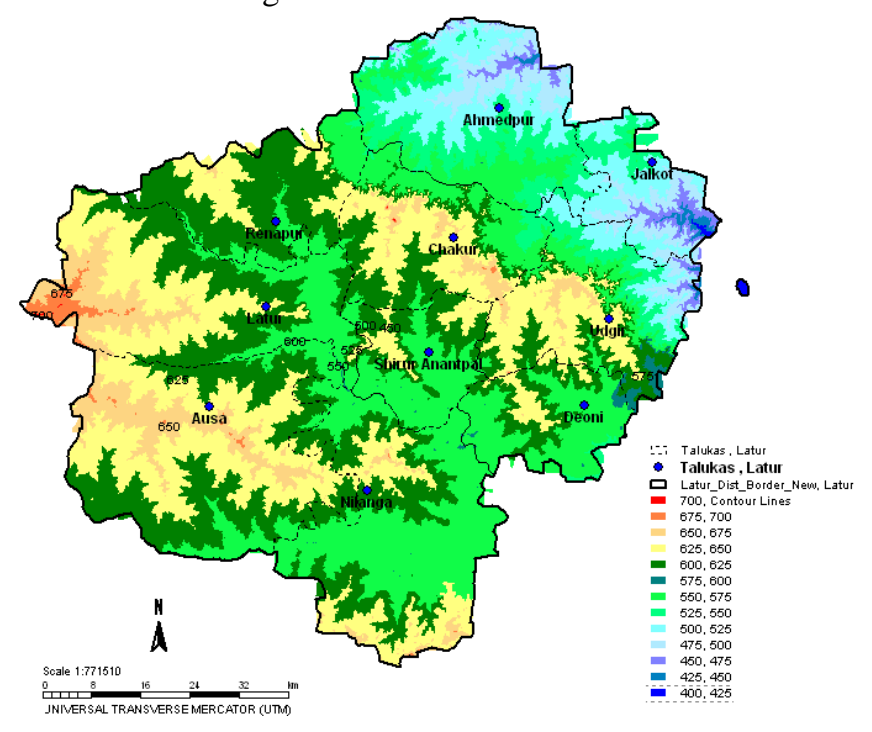

Fig. 2 Elevation Contours of Latur District.

TABLE 1 PARTICULARS OF COVERED ELEVATION AREA

\begin{tabular}{|c|c|c|}
\hline ID & Elevation (Mtr) & Area (Ha) \\
\hline 1 & 415 & 315 \\
\hline 2 & 425 & 2127 \\
\hline 3 & 450 & 8068 \\
\hline 4 & 475 & 26511 \\
\hline 5 & 500 & 49710 \\
\hline 6 & 525 & 47635 \\
\hline 7 & 550 & 179404 \\
\hline 8 & 575 & 5962 \\
\hline 9 & 600 & 182758 \\
\hline 10 & 625 & 170194 \\
\hline 11 & 650 & 46997 \\
\hline 12 & 675 & 5333 \\
\hline 13 & 700 & 83 \\
\hline
\end{tabular}

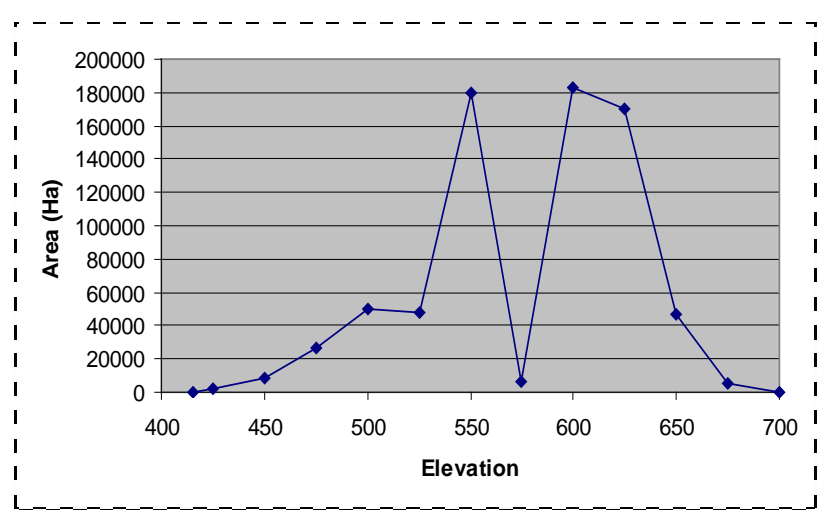

Fig. 3 Graphical representation of cover elevation area 


\section{EXTRACTION OF WATER BODIES FROM ELEVATION DATA}

The slope map was derived using the DEM. The Quantum GIS package is used to extract the reservoirs or lakes of the study area using polygonization. The polygonization utility creates vector polygons for all connected regions of pixels in the raster sharing a common pixel value. Each polygon is created with an attribute indicating the pixel value of that polygon. A raster mask may also be provided to determine which pixels are eligible for processing. The utility will create the output vector data source if it does not already exist, defaulting to GML format. The extracted water bodies are compared with hydrological map topo sheets for accuracy assessment. The slope map is shown in figure 4, and the extracted water body map for reservoirs/lakes of Latur district is shown in following figure 5.

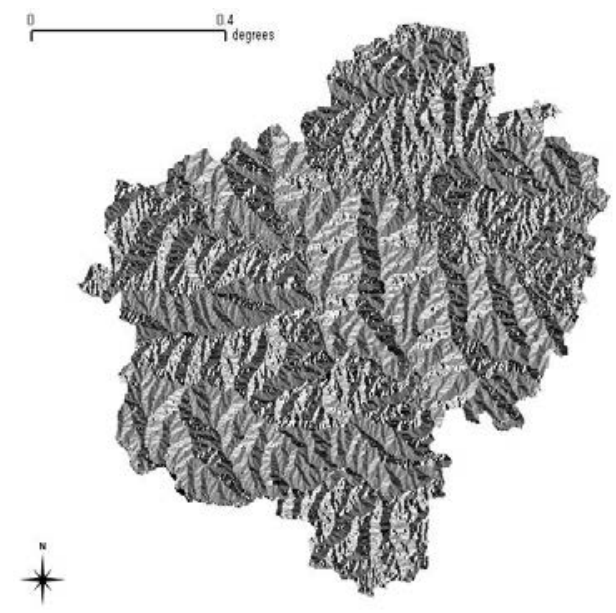

Fig. 4 Slope map of Latur district

The entire Latur district contains 08 major rivers namely Manjra, Manyad, Terna, Tavarja, Tiru, Lendi, Gharni and Devni. The length of each individual river in the district is Manjra 278 km, Manyad 95 km, Terna 122 km, Tavarja 47 km, Tiru 71 km, Lendi 63 km, Gharni 31 km, and Devni $55 \mathrm{~km}$.

The reservoirs map stored into spatial database. The total area covered by lakes/reservoirs in the district is 6262 hectares. The total average district area occupied by the reservoirs in the district is $0.86 \%$. The location and flow of each individual river in the district is shown in figure 6 .

\section{VI.WATER SCARCITY LACATIONS}

Taking all the above processes and results into account, the elevation maps, slope map, reservoir map and river map are imported into spatial data base of Latur district. Through examining the village's locations and processed results in the spatial database, the following figure 7 shows the critical locations of water scarcity regions.

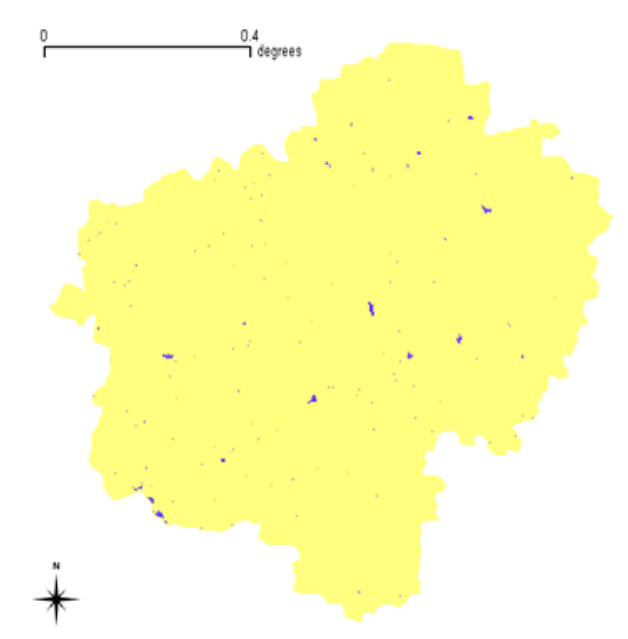

Fig. 5 Hydrological map (reservoirs/lakes) of Latur district

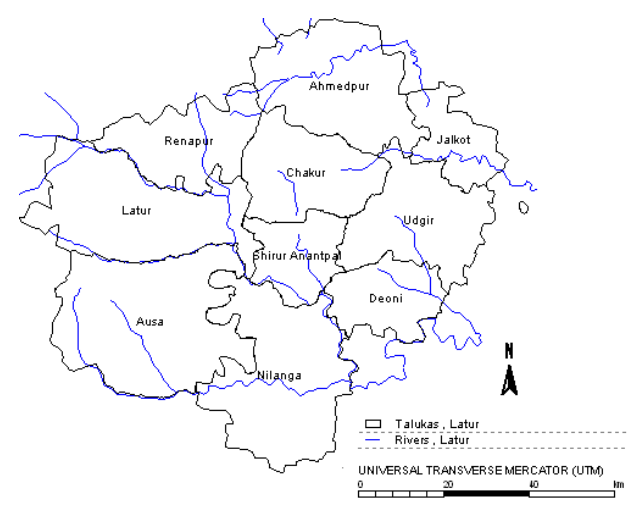

Fig. 6 River map of Latur district

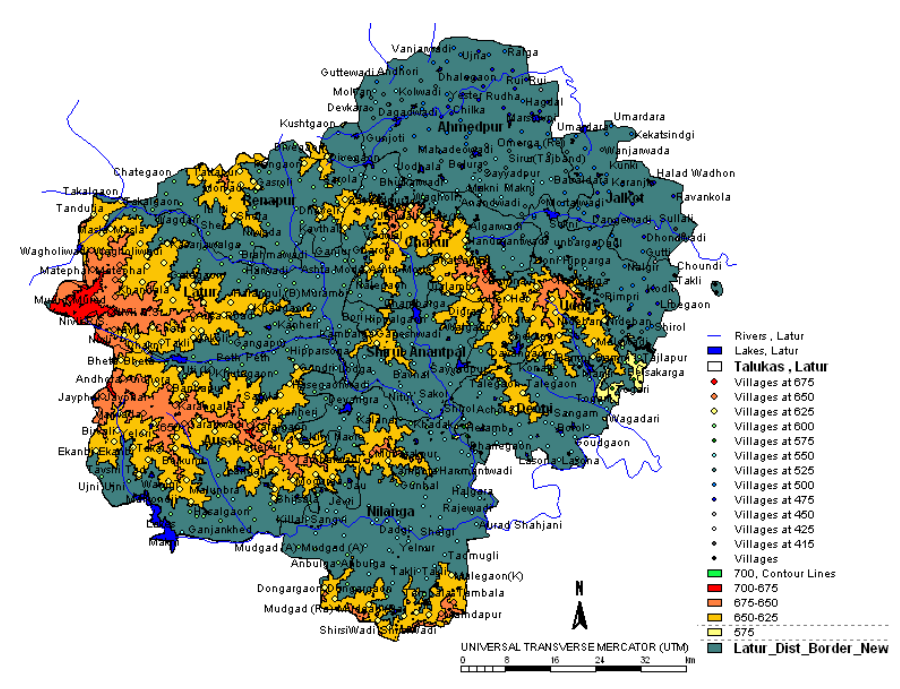

Fig.7 Water Scarcity map of Latur district. 


\section{B.G. Kodge}

The figure 7 shows the critical regions of water scarcity. The yellow colored polygon used to showcase normal water scarcity regions, the orange color polygon visualized for critical water scarcity regions and the red color polygon shows the very critical water scarcity region in Latur district.

\section{CONCLUSION}

This paper deals with different methods for analysis of elevation contour lines, water body (reservoirs and lakes) extraction, and finding critical zones of water scarcity in Latur district. Because the continuous overexploitations of natural resources like land, water and forest have caused serious threat to the local population of the semiarid region. Thus, problems like little scope for, declining ground water level and shortage of drinking water prevail. So some step should be taken for planning and developments of those areas which are fell in the water scarcity zones. It's for egovernance.

\section{REFERENCES}

[1] K.K. Gupta, et al, "Estimation of water harvesting potential for a semiarid area using GIS and remote sensing, Remote Sensing and Geographic Information Systems for Design and Operation of Water Resources Systems”, Proceedings of Rabat Symposium S3, IAHS Publ. No. 242, pp. 53-63, 1997.

[2] C. G Brown, K. Sarabandi, and L. E. Pierce, "Validation of the Shuttle Radar Topography Mission Height Data”, IEEE Transactions on Geoscience and Remote Sensing, Vol. 43, No. 8, pp. 1707-1715, 2005.

[3] Y.Gorokhovich, A. Voustianiouk, “Accuracy assessment of the processed SRTM-based elevation data by CGIAR using field data from USA and Thailand and its relation to the terrain characteristics”, Remote Sensing of Environment, Vol. 104, pp. 409415, 2006.

[4] A. P. Ozha, A. Kufoniyi, “Accuracy Assessment of Contour Interpolation From 1:50,000 Topographical Maps And Srtm Data For 1:25,000 Topographical Mapping”, The International Archives of the Photogrammetry, Remote Sensing and Spatial Information Sciences. Vol. XXXVII. Part B7. Beijing, pp. 1347-1354, 2008.

[5] Kocak, Güven , Büyüksalih, Gürcan; Jacobsen, Karsten, “Analysis of Digital Elevation Models Determined by High Resolution Space Images”, Karaelmas University Zonguldak, Turkey, pp. 15-20, 2009.

[6] B.G. Kodge, P.S. Hiremath, "Geographical Information System of Bidar district”, GIS Developments: the global geospatial Development Network, ISSN: 0971-9377 (Online E-magazine), Nov2009.

[7] P.S. Hiremath, B.G Kodge., "Generating contour lines using different elevation data file formats”, International Journal of Computer Science and Applications (IJCSA), Research Publications India, ISSN: 0974-1003. Vol. 3, No 1, pp. 19-25, 2010. 